STABILITY DIAGRAMS FOR FOURFOLD COORDINATION OF POLYVALENT METAL IONS IN MOLTEN MIXTURES OF HALIDE SALTS*

\title{
Z. Akdeniz
}

International Centre for Theoretical Physics, Trieste, Italy and Physics Department, University of Istanbul, Turkey

and

M. P. Tosi

Department of Theoretical Physics, University of Trieste, Italy and Materials Science Division, Argonne National Laboratory, Argonne, Illinols 60439, USA

\section{DISCLAIMER}

\begin{abstract}
This report was prepared as an account of work sponsored by an agency of the United States Government. Neither the United States Government nor any agency thereof, nor any of their employees, makes any warranty, express or implied, or assumes any legal liability or responsibility for the accuracy, completeness, or usefulı.ess of any information, apparatus, product, or process disclosed, or represents that its use would not infringe privately owned rights. Reference herein to any specific commercial product, process, or service by trade name, trademark, manufacturer, or otherwise does not necessarily constitute or imply its endorsement, recommendation, or favoring by the United States Government or any agency thereof. The views and opinions of authors expressed herein do not necessarily state or reffect those of the United States Government or any agency thereof.
\end{abstract}

*Work supported by the U.S. Department of Energy, BES-Materlals Sciences, ur ser contract \#W-31-109-ENG-38. 
Stability diagrams for fourfold coordination of polyvalent metal ions in molten mixtures of halide salts

\begin{abstract}
Z. Akdeniz
International Centre for Theoretical Physics, Trieste, Italy and Physics Department, University of Istanbul, Turkey

and

M. P. Tosi

Department of Theoretical Physics, University of Trieste, Italy and Materials Science Division, Argonne National Laboratory, Argonne, Illinois 60439, USA
\end{abstract}

\begin{abstract}
The stability of local fourfold coordination for divalent and trivalent metal ions in liquid mixtures of polyvalent metal halides and alkali halides is classified by means of structural coordinates obtained from properties of the elements. In parallel with earlier classifications of compound crystal structures and molecular shapes, the elemental properties are taken from first - principles calculations of valence electron orbitals in atoms, in the form of (i) the nocial radii of Andreoni, Baldereschi and Guizzetti or (ii) the pseudopotential radii of Zunger and Cohen. As a third alternative a classification based on Pettifor's phenomenological chemical scale of the elements is also considered. The alternative structural classification schemes that are developed from these elemental properties are generally successful in distinguishing molten mixtures in which the available experimental evidence indicates long-lived fourfold coordination of polyvalent metal ions. In addition, Pettifor's chemical scale scheme is useful in sorting out finer details of local coordination in the liquid state.
\end{abstract}




\section{Introduction}

The prediction of the stable structure taken by an atomic aggregate in given thermodynamic conditions, starting from properties of its atomic constituents, has been a challenging problem for many years. As an alternative to full quantal calculations, a semi-empirical approach of "structure sorting" has been very popular for the structural classification of broad families of compounds. In the case of crystalline solids, this leads to structural maps for families of binary comprounds, based on parameters of the elements (St John and Bloch 1974; Chelikowsky and Phillips 1978; Zunger and Cohen 1979; Andreoni, Baldereschi, Bièmont and Phillips 1979; Zunger 1980; Burdett, Price and Price 1981; Villars 1983, 1984, 1985; Andreoni 1985; Pettifor 1986; for a general review see Mooser 1986). The same approach has been adopted in the classification of the equilibrium shapes taken by small polyatomic molecules and atomic clusters (Andreoni, Galli and Tosi 1985; Andreoni and Galli 1987).

Extension of these methods to the classification of liquid structures can be expected to be at least as useful, but certainly more difficult. While a promising start has been made in the case of silicon to first - principles calculations of disordered structures (Car and Parrinello 1988), the theory of liquid structure still relies heavily on the use of pair (or more complex) interatomic potentials. On the other hand, it is hard to draw sharp distinctions between the liquid structures taken by different compounds of the same family, even if one compares them in somehow corresponding thermodynamic states - for instance by referring to the liquid near freezing at atmospheric pressure. Nevertheless, correlations between crystal structure maps and liquid state diffraction data have already been noticed for $M X_{2}$ double-octet compounds (Rovere and Tosi 1986).

The structure sorting approach can be directly applied to at least one structural problem in liquid state physics, concerning the local coordination taken by 
polyvalent metal ions when they are supplied with an excess of halogen ions through mixing their halide salts with alkali halides in the molten state (Akdeniz, Wang $\mathrm{Li}$ and Tosi 1988). There is ample evidence in the literature on this structural aspect of molten salt mixtures, although in most cases the evidence is not as direct as in a diffraction experiment. In order to embrace a large number of such mixtures, which may show different behaviours with varying concentration $c$ of polyvalent metal halide, we shall refer as much as possible to a "stoichiometric" composition given by $c=1 / 3$ for divalent ions and $c=1 / 2$ for trivalent ones. In many' systems, the data indicate fourfold coordination of divalent or trivalent metal ions by halogens, of tetrahedral or distorted tetrahedral type. Such local coordination may somewhat loosely be referred to as a "complex". It is not, however, a general phenomenon occurring for all polyvalent metal ions. In a number of systems the data exclude the formation of complexes, in the sense that none of the characteristics that go with it (for instance, a typical behaviour of the enthalpy and entropy of mixing versus concentration or structures in the Raman scattering spectrum) are observed. The polyvalent metal ions in such mixtures presumably have a loose average coordination of order six. Formation of long-lived octahedral complexes has also been reported for several trivalent ions in molten salt mixtures, the "stoichiometric" composition then being $c=1 / 4$.

The purpose of the present work is a comprehensive classification of trends in complex stability with varying chemical species, $i$. e. in dependence of the polyvalent metal $M$, the halogen $X$ and the alkali $A$, in liquid mixtures of $M X_{2}$ or $M X_{3}$ with $A X$ (abbreviated in the following as $\mathrm{M}-\mathrm{A}(\mathrm{X})$ ) at stoichiometric composition. It extends our previous work under two main aspects, namely (i) a broad variety of divalent and trivalent metal ions, including transition and rare earth metal ions, will be considered and (ii) various alternative schemes of structural sorting will be adopted. The usefulness of each scheme will be taken as proven from its applications to crystal structure classifications and the various predictions will be examined for the insight that they may give on the present liquid structure problem. 


\section{The evidence}

The word "complex" has been used in the literature with somewhat different meanings by different authors. A strict viewpoint uses it to denote a kinetic entity persisting in the liquid over times appreciably longer than typical times for translational and rotational diffusion, i. e. longer than $10^{-11} \mathrm{~s}$ and possibly as long as $10^{-5} \mathrm{~s}$. The same expression is still applied by some authors to systems in which polyvalent metal ions are fluctuating between fourfold-coordinated and more highly coordinated states over a time scale which is just sufficiently long for some characteristic structure to be visible in a Raman scattering spectrum, the time scale of the experiment being then of order $10^{-13} \mathrm{~s}$. As an example of a borderline case of the latter type we may quote the $\mathrm{CaCl}_{2} \cdot 2 \mathrm{KCl}$ mixture, as examined by Raman scattering and discussed in the work of Sakai, Nakamura, Umesaki and Iwamoto (1984). Data analysis has led the authors to propose coexistence of tetrahedral-type and octahedral-type coordinations for the $\mathrm{Ca}$ ion. One may expect in this case fairly rapid fluctuations for each $\mathrm{Ca}$ ion between these two preferred coordinations, given the good ionicity of the melt.

Clearly, we are first of all interested in identifying systems of strong stability for fourfold coordinated states at stoichiometric composition, in terms of observed characteristic behaviours that will be specified immediately below. In addition, however, we shall also try to recognize systems in which the stability of such states may be described as marginal, since these naturally should tend to cluster in transitional regions. The systems for which the available evidence excludes the presence of fourfold coordinated states, except perhaps on a very fleeting and as yet unresolved time scale, should in turn lie in separate regions of a structural map, with the possibility of further distinction between stable octahedral coordination and loose coordination due to rapid fluctuations. We shall therefore classify the systems of present interest on the basis of the available experimental evidence into three classes, i. e. strong stability, marginal stability and instability of fourfold courdination. 
We shall use the word "complex" without further qualifications as an abbreviation for fourfold coordinated state and shall include in the st-called marginal stability class cases of recognized coexistence between fourfold and more highly coordinated states as well as systems for which the evidence that we have found yields ambiguous indications.

The techniques of $X$-ray diffraction and neutron diffraction are, of course the most direct for the determination of local coordination in liquids. Such measurements are to our knowledge available only for the Be- $\mathrm{Li}(\mathrm{F})$ system (Vaslow and Narten 1973), the $\mathrm{AlCl}_{3} . \mathrm{LiCl}$ mixture (Takahashi, Muneta, Koura and Ohno 1985; Biggin, Cummings, Enderby and Blander 1985), the Al-Na(Cl) system (Takahashi, Maruoka, Koura and Ohno 1986) and the Al-K(Cl) system (Saboungi, Price and Blander 1988, private communication). In all cases the observed characteristics of the pair distribution functions show strong stability of $\left(\mathrm{BeF}_{4}\right)^{2-}$ and $\left(\mathrm{AlCl}_{4}\right)^{-}$complexes. Fortunately, the same systems have also been studied by indirect techniques involving thermodynamic measurements (Holm and Kleppa 1969), Raman scattering (Øye, Rytter, Klaeboe and Cyvin 1971; Quist, Bates and Boyd 1972) and infrared emission spectroscopy (Hvistendahl, Klaeboe, Rytter and Øye 1984). Further confidence is thus gained in conclusions based on these techniques for other systems.

A large number of Raman scattering experiments have been performed on $\mathrm{M}-\mathrm{A}(\mathrm{X})$ systems. We have been able to find relevant data in the work of Bues 1955 (Zn-K(Cl)), Janz and James $1963(\mathrm{Hg}-\mathrm{K}(\mathrm{Cl}))$, Ellis $1966(\mathrm{Zn}-\mathrm{K}(\mathrm{Br})$ and $\mathrm{Zn}-\mathrm{A}(\mathrm{Cl})$ with A $=\mathrm{Li}, \mathrm{K}, \mathrm{Rb}, \mathrm{Cs})$, Clarke and Hester 1969 (In-A(Cl) with $\mathrm{A}=\mathrm{Li}, \mathrm{K}, \mathrm{Cs})$, Begun, Boston, Torsi and Mamantov 1971 (Al-Na(Br) and Al-Cs(I)), Maroni 1971 and Maroni, Hathaway and Cairns $1971(\mathrm{Mg}-\mathrm{K}(\mathrm{X})$ with $\mathrm{X}=\mathrm{Cl}, \mathrm{Br}, \mathrm{I})$, Øye et al $1971(\mathrm{Al}-\mathrm{K}(\mathrm{Cl})$ ), Clarke, Hartley and Yuroda $1972(\mathrm{Cd}-\mathrm{K}(\mathrm{Br})$ and $\mathrm{Cd}-\mathrm{A}(\mathrm{Cl})$ with $\mathrm{A}=\mathrm{Li}, \mathrm{K}, \mathrm{Cs})$, Quist et al 1972 (Be-A(F) with $\mathrm{A}=\mathrm{Li}, \mathrm{Na})$, Øye, Rytter and Kláeboe 1974 (In-K(Cl)), Maroni, Hathaway and Papatheodorou $1974(\mathrm{La}-\mathrm{K}(\mathrm{Cl}))$, Papatheodorou $1975\left(\mathrm{Cs}_{2} \mathrm{NaLaCl}_{6}\right.$ and 
La-A(Cl) with $A=K, C s)$, Brooker $1975(\mathrm{Mg}-\mathrm{A}(\mathrm{Cl})$ with $\mathrm{A}=\mathrm{K}, \mathrm{Cs})$, Gilbert, Fung, Mamantov and Begun 1975 (Au-K(Cl)), Gilbert, Mamantov and Begun 1975 (Al-A(F) with $\mathrm{A}=\mathrm{Li}, \mathrm{Na}, \mathrm{K}, \mathrm{Cs})$, Papatheodorou $1977\left(\mathrm{Cs}_{2} \mathrm{NaYCl}_{6}\right.$ and $\mathrm{Y}-\mathrm{A}(\mathrm{Cl})$ with $\mathrm{A}=\mathrm{Li}, \mathrm{K}$, Cs), Brooker and Huang $1980(\mathrm{Mg}-\mathrm{A}(\mathrm{Cl})$ with $\mathrm{A}=\mathrm{Li}, \mathrm{Na}, \mathrm{Rb}, \mathrm{Cs})$, Bues, Atapoor and Popperl 1983 (Ca-K(I)), Emons, Horibech and Kiessling $1984(\mathrm{Ca}-\mathrm{A}(\mathrm{Br})$ with $\mathrm{A}=\mathrm{Li}, \mathrm{K}$, $\mathrm{Rb})$ and Sakai et al $1984(\mathrm{Ca}-\mathrm{A}(\mathrm{Cl}), \mathrm{Sr}-\mathrm{A}(\mathrm{Cl})$ with $\mathrm{A}=\mathrm{K}, \mathrm{Rb}, \mathrm{Cs}$ and $\mathrm{Ba}-\mathrm{K}(\mathrm{Cl}))$. The presence of stable complexes in the liquid mixture is revealed by fairly narrow bands superposed on a spectral background rising rapidly at low frequency. The band peak frequencies can be put in correspondence with Raman frequencies associated with the fourfold-coordinated ion in crystals or in aqueous solutions. Polarization studies give further information on the stable entity which is being observed -- in particular, the band associated with the totally symmetric stretching mode of a tetrahedral complex is especially prominent and easily identified. In the absence of such prominent spectral features, a detailed analysis of the observed spectrum still permits identification of marginal stability, as in the aforementioned work of Sakai et al (1984) on $\mathrm{CaCl}_{2} \cdot 2 \mathrm{KCl}$. We have also tentatively attributed marginal stability to complexes in mixtures where a well defined shoulder is seen in the Raman spectrum without further analysis of the data. Finally, we have interpreted the data of Prisyazhnyi, Baranov and Sunegin (1978) on molten $\mathrm{BeCl}_{2}$ as indicative of at least marginal stability for $\left(\mathrm{BeCl}_{4}\right)^{2-}$ complexes in Be - alkali chloride systems.

Infrared emission and absorption spectra are also available for a few systems from the work of Wilmhurst $1963(\mathrm{M}-\mathrm{A}(\mathrm{Cl})$ with $\mathrm{M}=\mathrm{Zn}, \mathrm{Cu}$ and $\mathrm{A}=\mathrm{Li}, \mathrm{K})$ and of Hvistendahl et al $1984(\mathrm{Al}-\mathrm{A}(\mathrm{Cl}))$ and have been discussed by the authors in relation to the problem of complex stability. Of special interest among optical measurements are the electronic absorption spectra in the near-visible and visible for transition metal ions in liquid chloride mixtures. The coordination geometry of the ion is directly reflected in the spectrum through the splitting that it induces in the d-electron energy levels. Reviews of the data have been given by Gruen and McBeth 
(1963) and Gruen (1964). Tetrahedral-type coordination is the only one observed for several divalent ions $\left(\mathrm{Ni}^{2+}, \mathrm{Cu}^{2+}, \mathrm{Cr}^{2+}, \mathrm{Fe}^{2+}, \mathrm{Co}^{2+}\right.$ and $\left.\mathrm{Mn}^{2+}\right)$ in a $\mathrm{LiCl}-\mathrm{KCl}$ eutectic solvent, with an appreciable distortion from tetrahedral symmetry for the three former ions. Stability of $\left(\mathrm{NiCl}_{4}\right)^{2-}$ in pure chloride solvents as well as of $\left(\mathrm{NiBr}_{4}\right)^{2-}$ in pure bromide sclvents is confirmed by the work of Smith and Boston $1965(\mathrm{Ni}-\mathrm{A}(\mathrm{Cl})$ and $\mathrm{Ni}-\mathrm{A}(\mathrm{Br})$ with $\mathrm{A}=\mathrm{Li}, \mathrm{K}, \mathrm{Cs}$ ), with the possible exceptions of the $\mathrm{LiCl}, \mathrm{NaCl}$ and $\mathrm{LiBr}$ soivents. On the other hand, only octahedral coordination is observed for trivalent $\mathrm{Cr}^{3+}$ in the $\mathrm{LiCl}-\mathrm{KCl}$ solvent, whereas for $\mathrm{V}^{2+}, \mathrm{V}^{3+}$ and $\mathrm{Ti}^{3+}$ the spectra show a shift with increasing temperature from predominant octahedral coordination to equilibrium between octahedral and distorted tetrahedral configurations. The shift can be strengthened by replacing the $\mathrm{LiCl}-\mathrm{KCl}$ solvent with an appropriate different solvent (e. g. $\mathrm{CsGaCl}_{4}$ in the case of $\mathrm{TiCl}_{3}$ ) Finally, the $\left(\mathrm{PtCl}_{4}\right)^{2-}$ complex in square planar configuration has been observed in $\mathrm{Pt}-\mathrm{A}(\mathrm{Cl})$ systems with $\mathrm{A}=\mathrm{Li}, \mathrm{K}, \mathrm{Cs}$ (Papatheodorou and Smith 1973).

Thermodynamic properties bearing on the problem at hand are the enthalpy of mixing from calorimetric measurements and the partial Gibbs free energies of mixing from emf measurements in galvanic cells. Combination of the two experiments allows the evaluation of the entropy of mixing. Data are available from the work of McCarty and Kleppa 1964 Pb-AíCl)), Kleppa and McCarty 1966 (Mg-A(Cl)), Holm and Kleppa 1969 (Be-A(F) with A = Li, K, Rb), Ikeuchi and Krohn 1969 ( $\mathrm{Mg}-\mathrm{A}(\mathrm{Cl})$ with $\mathrm{A}=\mathrm{Na}, \mathrm{K}, \mathrm{Cs})$, Papatheodorou and Kleppa $1970\left(\mathrm{Ni}-\mathrm{A}^{\prime} \mathrm{Cl}\right)$ ), 1971a (M-A(Cl) with $\mathrm{M}=\mathrm{Mn}, \mathrm{Fe}, \mathrm{Co}$ ) and 1971b (Cd-A(Cl) with $\mathrm{A}=\mathrm{Li}, \mathrm{Cs})$, Østvold 1972a (Ca-A $(X)$ with $X=\mathrm{Cl}, \mathrm{Br}$; $\mathrm{Sr}-\mathrm{A}(\mathrm{Cl})$ with $\mathrm{A}=\mathrm{Na}, \mathrm{K}, \mathrm{Rb}, \mathrm{Cs} ; \mathrm{Sr}-\mathrm{A}(\mathrm{Br})$; $\mathrm{Ba}-\mathrm{A}(\mathrm{Br})$ with $\mathrm{A}=$ $\mathrm{Na}, \mathrm{K}, \mathrm{Rb}, \mathrm{Cs})$ and 1972b (Mn- $\mathrm{A}(\mathrm{Ci})$ with $\mathrm{A}=\mathrm{Li}, \mathrm{Na}, \mathrm{K}, \mathrm{Rb})$, Dutt and Østvold 1972 (Co-A(Cl) with $\mathrm{A}=\mathrm{Li}, \mathrm{Na}, \mathrm{K}, \mathrm{Rb}$ ), Papatheodorou and Kleppa 1974 (Ce-A(Cl)), Papatheodorou and Østvold 1974 (La-A(Cl)), Hong and Kleppa 1978 (M-A(F) with M $=\mathrm{Mg}, \mathrm{Ca}, \mathrm{Sr}, \mathrm{Ba}$ and $\mathrm{A}=\mathrm{Li}, \mathrm{Na}, \mathrm{K})$ and Papatheodorou, Waernes and Østvold 1979 $(Y-A(C l))$. The need for measurements on a wide concentration range implies that 
the system is usually at higher temperatures than in a Raman scattering or optical absorption experiment.

In the ideal case of infinitely strong complex stability, both the enthalpy and the entropy of mixing would show sharp minima at stoichiometric composition. However, calculations by Ikeuchi and Krohn (1969) show that the sharp minimum in the entropy of mixing is already reduced to a small notch if the reaction constant for dissociation of $\left(\mathrm{MX}_{4}\right)^{2-}$ becomes of order $10^{-2}$, which at $\mathrm{c}=1 / 3$ would still correspond to more than $80 \%$ of the divalent ions being on average buund in complexes. In practice most of the evidence concerns the enthalpy of mixing $\Delta \mathrm{H}$ and is commonly interpreted by constructing the so-called interaction parameter $\lambda=\Delta \mathrm{H} /[\mathrm{c}(1-\mathrm{c})]$ as a function of concentration. The presence of complexes is then inferred from the presence of a well defined minimum at or near stoichiometric romposition. By comparison with the indications from other types of measurements it appears that this criterion is quite restrictive. For example in the $\mathrm{Be}-\mathrm{Li}(\mathrm{Fi})$ system both $\Delta \mathrm{H}$ and $\lambda$ show only very broad minima in the region around $\mathrm{c} \approx 0.3$ (Holm and Kleppa 1969), although the stability of $\left(\mathrm{BeF}_{4}\right)^{2-}$ complexes is demonstrated by $X$-ray diffraction (Vaslow and Narten 1973) and by Raman scattering (Quist et al 1972). We have therefore tended to give less weight to the thermodynamic evidence, but in the lack of other measurements we have tentatively accepted the conclusions drat $n$ from the dependence of the interaction parameter on concentration and have inferred marginal stability of fourfold configurations at stoichiometric composition when $\lambda$ is not flat and is at least $10 \mathrm{kcal} / \mathrm{mole}$ in magnitude. We have tentatively inferred instability when $\lambda$ fails to satisfy both criteria.

With the benefit of the authors' discussion of their own data and following the criteria that we have exposed above, we have achieved a classification of fourfold coordination for polyvalent ions into the three indicated classes, i. e. stable, 
marginally or possibly stiable, and unstable. The results will be reported at a later stage, after we shall have presented the coordinates by which each system may be labelled. We stress that in some systems the available evidence is insufficient to allow more than a tentative assignment and that we have also met a few cases where conflicting indications could be obtained from different measurements. We shall comment on such systems as appropriate in the final discussion in section 4 .

\section{Structural maps}

We consider first the construction of structural parameters starting from the pseudopotential radii $S_{l}(1=0,1)$ of Zunger and Cohen (1979) and from the nodal radii $N_{l}(l=0,1)$ of Andreoni, Baldereschi and Guizzetti (unpıblished). We recall that $S_{l}$ is defined as the classical turning point of the l-component of the pseudopotential derived from atomic calculations in the local density approximation, while $\mathrm{N}_{l}$ is defined as the outermost node of the atomic valence electron orbital of angular momentum 1 from all-electron atomic calculations.

In the pseudopotential Zunger-Cohen (ZC) scheme one defines for each element $\mathrm{E}$ the elemental parameters

$$
R_{\sigma}^{E}=S_{0}+S_{1}
$$

and

$$
R_{\pi}^{E}=\left|S_{0}-S_{1}\right|
$$

Compound parameters are then constructed for eacri binary cumpound of elements $A$ and $B$ as

$$
Y_{A B}^{Z C}=\left|R_{\sigma}^{A}-R_{\sigma}^{B}\right|
$$


and

$$
X_{A B}^{Z C C}=R_{\pi}^{A}+R_{\pi}^{B}
$$

With specific reference to $A B$ octet compounds and $A B_{2}$ double-octet (DO) compounds, Burdett et al (1981) have shown that successful sorting of crystal structures is achieved in plots using the elemental parameters $R_{\sigma} A$ and $R_{\sigma} B$ as coordinates. The same choice of coordinates is successful in separating linear DO $\mathrm{AB}_{2}$ molecules from bent ones (Andreoni et al 1985). Cn the other hand, use of the compound parameters defined in eqns (3) and (4) leads to very poor structure sorting for the $\mathrm{DO} A B_{2}$ crystals (Burdett et al 1981). Evidently, we shall have to consider suitable combinations of elemental or compound parameters for each mixture in searching for two-dimensional structural plots for the systems of present interest.

In the nodal radii scheme proposed by Andreoni (1985), the elemental parameters are instead defined as

$$
y_{E}=\frac{1}{4}\left(N_{0}^{E}+3 N_{1}^{E}\right)
$$

and

$$
X_{E}=\frac{1}{4}\left(3 N_{0}^{E}-N_{1}^{E}\right)
$$

The compound parameters are chosen as

$$
Y_{A B}=y_{B}-y_{A}
$$

and

$$
x_{A B}=x_{A}+x_{B}
$$

or (for $\mathrm{AB}_{2}$ compounds)

$$
X_{A B}^{\prime}=2 X_{A}+X_{B}
$$

Use of $\mathrm{Y}_{\mathrm{AB}}$ and $\mathrm{X}_{\mathrm{AB}}$ (or $\mathrm{X}_{\mathrm{AB}}^{\prime}$ ) as coordinates yields successful sorting of crystals structures (Andreo .i 1985), whereas molecular shapcs can be classified by adopting either the pair $\left(X_{A B}^{\prime}, Y_{A B}\right)$ of compound coordinates or the pair $\left(y_{A}, y_{B}\right)$ of 
elemental coordinates (Andreoni et $\underline{\text { al 1985). }}$

We may briefly comment at this point on the aims of siructure sorting on the basis of the atomic parameters recalled above. Of course, structure sorting has a long history, during which various indices such as sets of ionic radii or Pauling's electronegativities have been used. The aim of the pseudopotential and nodal radii schemes is to avoid empirical parametrizations by translating such physical indices into precisely defined parameters of the valence electron orbitals, which are evaluated from first-principles calculations on the atoms. The elemental parameters in eqns (1) and (2) or (5) and (6) correlate to a considerabie extent with classical ionic radii (see e. g. Zunger 1980), although they strictly are properties of the valence electron orbitals rather than of ionic cores and carry information on chemical bonding properties in addition to geometric core size.

It has also proved possible, on the other hand, to translate the recent progress in understanding the cohesion of bulk solids from first-pririciples calculations into a phenomenological chemical scale of the elements (Pettifor 1984). This approach orders all the elements along a single axis $\chi$ so that the Mendeleev-type features of the periodic table are preserved. Such a one-dimensional ordering of the elements provides excellent sorting of crystal structures for a large variety of binary compounds with given stoichiometry $A_{m} B_{n}$ in a plot using the pair $\left(\chi_{A}, \chi_{B}\right)$ as coordinates (Pettifor 1986).

Let us now proseed to the selection of coordinates for two-dimensional structural maps of the liquid mixtures of present interest. The guidelines have already been described in relation to the nodal radii scheme (Akdeniz et al 1988). A broad feature of the data for alkaline earth - alkali halide mixtures is that the stability of complexes decreases as the alkaline earth component is varied from Be to Ba and as the alkaii is varied from $C s$ to $L i$. This suggests that the difference $X_{M X}-X_{L} X=x_{M}-x_{A}$ is a 
relevant structural coordinate. A more detailed examination of the evidence is necessary to identify a second coordinate. The dependence of the stability of complexes on the halogen species has not been so far studied experimentally in a fully systematic manner, and in particular very little evidence is available for iodides. Nevertheless the evidence seems to indicate some tendency to increased stability from the fluoride to the chloride and bromide. Further hints come from comparisons of the behaviour of specific chlorides, for instance the comparison of the $\mathrm{BeCl}_{2}$ melt and the $\mathrm{Mg}-\mathrm{Na}(\mathrm{Cl})$ and $\mathrm{Ca}-\mathrm{K}(\mathrm{Cl})$ systems, through which stability of fourfold coo:dination appears to progressively weaken. All these features emerging from the body of available data can be incorporated into structure sorting by the choice of $Y_{M X}+x_{A X}=2 y_{X}-y_{M}-y_{A}$ as the second siructural coordinate in the nodal radii scheme.

The structural map obtained with the above choice of coordinates is shown in Figure 1. We have indicated with a dot those systems for which the evidence is in favour of good stability for fourfold coordination. The other systems are marked with a lozenge when the available evidence tends to exclude the presence of fourfold coordination and with a circle in cases of marginal or possible stability. Each system is labelled by the notation $\mathrm{M}-\mathrm{A}(\mathrm{X})$, except for the chlorides where the halogen label has been omitted for the sake of clarity.

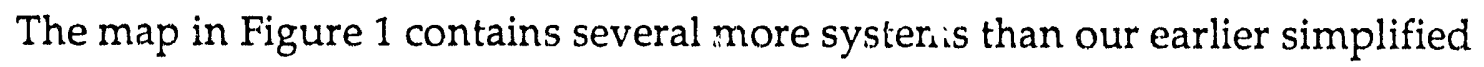
plot, but is still incomplete relative to the available evidence. It does not include transition metal or rare eath ions nor heavy ions such as $\mathrm{Pb}^{2+}, \mathrm{Hg}^{2+}$ and $\mathrm{Au}^{3+}$, in the lack of nodal radii for these elements. In view of its incompleteness we shall not comment in detail on it, but shall merely remark that a straight boundary through the marginal stability systems $\mathrm{Ca}-\mathrm{K}(\mathrm{Cl})$ and $\mathrm{Ca}-\mathrm{Li}(\mathrm{Br})$, as shown by the shaded line in Figure 1, achieves almost complete separation of the non-complexing systems among the mixtures that are present in the plot. The only exceptions are $\mathrm{Mg}-\mathrm{Li}(\mathrm{F})$ 
and $\mathrm{Mg}-\mathrm{Li}(\mathrm{Br})$, on which we shall return later. It is also seen that the region of strong stability can be further delimited in the map, as shown by the full lines in Figure 1.

The guidelines that we have summarized above are again useful in identitying appropriate structural coordinates in the $\mathrm{ZC}$ pseudopotential scheme and in Pettifor's chemical scale scheme. In the former we find, with the definitions given earlier in eqns (3) and (4), that successful structural coordinates for each mixture can be obtained as

$$
X_{M-A(X)}=X_{M X}^{Z C}-X_{A X}^{Z C}=R_{\pi}^{M}-R_{\pi}^{A}
$$

and

$$
Y_{M-A(X)}=Y_{M X}^{Z C}+Y_{A X}^{Z C}=\left|R_{\sigma}^{M}-R_{\sigma}^{X}\right|+\left|R_{\sigma}^{A}-R_{\sigma}^{X}\right|
$$

The structural map obtained with the values of the pseudopotential radii reported by Zunger (1980) is shown in Figure 2. Finally, in the chemical scale scheme appropriate coordinates for each mixture are found to be

$$
X_{M-A(X)}=x_{M}-x_{A}
$$

and

$$
Y_{M-A(X)}=\chi_{M}+\chi_{A} \cdot 2 \chi_{X}
$$

leading to the structural map shown in Figure 3. Here, the $Y$ coordinate for the fluoride mixtures has been raised by 2 for compactness, as shown by the breaks in the vertical scales of the Figure.

\section{Discussion}

It is immediately seen from Figures 2 and 3 that both maps achieve very good separation between stability and instability of fourfold coordination. The strong stability cases are clustered in the bottom left quadrant of Figure 2 and in the upper 
right-hand part of the main diagonal in Figure 3. The discussion of the two maps can be carried out in parallel to some extent.

We remark first of all that the Be - alkali chloride systems, that we have included in the intermediate class of possible complex stability in the lack of data except on the pure $\mathrm{BeCl}_{2}$ melt (Prisyazhnyi et al 1978), lie well inside the region of strong stability. Subject to experimental verification, we infer that $\left(\mathrm{BeCl}_{4}\right)^{2-}$ complexes may be strongiy stable in these mixtures.

We also note that two systems that we have classified as non-complexing, i.e. $\mathrm{Pb}-\mathrm{Li}(\mathrm{Cl})$ and $\mathrm{Pb}-\mathrm{Na}(\mathrm{Cl})$, appear to lie in a region of strong stability. We stress that our classification of these systems is solely based on enthalpy data (McCarty and Kleppa 1964) and suggest that they would be good candidates for Raman scattering experiments. Similar comments apply to $\mathrm{Mg}-\mathrm{Li}(\mathrm{Br})$ and to $\mathrm{Mg}-\mathrm{Li}(\mathrm{F})$, althoug' the suggestions coming from our maps are clearly weaker in these cases. We have classified them as non-complexing on the basis of thermodynamic data by Hong and Kleppa (1978) and Østvold (1972).

Having commented on those few systems that are clear exceptions to general patterns in our structural maps, we may now try to make these patterns more evident by drawing approximate boundary lines inside the maps. We stress again that the nature of the evidence is not such as to ensure uniform reliability to our assignments and that gradual rather than sharp changes of behaviour should be expected in the liquid state. Our boundary lines should therefore be understood as only marking the approximate locations of transitional regions in structural behaviour.

Starting from the map in Figure 2, it seems natural to focus first on the $Y-A(C l)$ systems for a possible boundary, since there is good evidence for stable $\left(\mathrm{YCl}_{6}\right)^{3-}$ states 
in these systems (Papatheodorou 1977, Papatheodorou et al 1979). Above this boundary, shown by shaded lines in Figure 2, are found the vast majority of the systems in which fourfold coordination appears to be unstable, together with a few

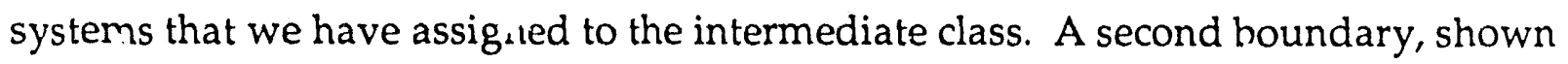
by the full lines, can be drawn to delimit the region of strong stabilit;. We have drawn the latter boundary by referring to a few systems for which the evidence in favour of stable fourfold coordination is strong, i. e. Be- $\mathrm{Li}(\mathrm{F})$ (Vaslow and Narten 1973) and the Pt-A(Cl) systems (Papatheodorou and Smith 1973). The abnve approximate partition of the map in Figure 2 into three regions of strong stability, marginas or possible stability and instability for fourfold coordinated states appears to be the most use that can be made of it. However, we shall comment further below on the Li-based systems that are seen to cluster in the bottom right-hand corner of the map.

The map in Figure 3 can be partitioned in a way which is considerably more significant. Again a shaded boundary line drawn through the $\mathrm{Y}-\mathrm{A}(\mathrm{Cl})$ systems and continued as indicated through fluorides separates out in the botiom left-hand corner of the map most of the alkaline earth systems where fourfold coordination is unstable or marginally stable against loose higher coordinations. However, immediately above this boundary are found the $\mathrm{La}-\mathrm{A}(\mathrm{Cl})$ and $\mathrm{Ce}-\mathrm{A}(\mathrm{Cl})$ systems in which octahedral coordination appears to be almost as strongly stable as in $\mathrm{Y}-\mathrm{A}(\mathrm{Cl})$, the $\mathrm{La}$ and $\mathrm{Ce}$ ions being practically indistinguishable in their structural parameters and coordination behaviour (Maroni et al 1974, Papatheodorou and Østvold 1974. Papatheodorou and Kleppa 1974, Papatheodorou 1977). Next to these are found the Ti-based and V-based chlorides, in which octahedral and distorted tetrahedral configurations are competitive in dependence on temperature (Gruen and McBeth 1963). A further region can thus be delimited to enclose the systems where well defined octahedral configurations are stable or dominant at low temperature. This is shown by the full line through the $\mathrm{Cr}$-based chlorides, in which the coordination state depends on the valency of the $\mathrm{Cr}$ ion (Gruen and McBeth 1963). This line is 
part of the boundary delimiting the systems of strong stability for fourfold coordination, which can be completed as shown by the full line along the main diagonal in Figure 3. In drawing this last boundary we have mostly relied on the evidence for Al- $\mathrm{Li}(\mathrm{Cl})$ (Takanashi et al 1985, Biggin et al 1985), $\mathrm{Al}-\mathrm{Na}(\mathrm{Br})$ (Begun et al 1971), $\mathrm{Pt}-\mathrm{Li}(\mathrm{Cl})$ (Papatheodorou and Smith 1973), $\mathrm{Co}-\mathrm{Na}(\mathrm{Cl})$ (Papatheodorou and Kleppa 1971a, Dutt and Østvold 1972) and $\mathrm{Mn}-\mathrm{Na}(\mathrm{Cl})$ (Papatheodorou and Kleppa 1971a, Zstvold 1972b).

Two further points are worth noticing with regard to the map in Figure 3. Firstly, the systems that are known to form square planar complexes, i. e. $\mathrm{Pt}-\mathrm{A}(\mathrm{Cl})$ (Papatheodorou and Smith 1973) and $\mathrm{Au}-\mathrm{K}(\mathrm{Cl})$ (Gilbert, Fung, Mamantov and Begun 1975), are seen to lie close to each other in the middle of the stability region. The $\mathrm{Ni}-\mathrm{A}(\mathrm{Cl})$ and $\mathrm{Cu}-\mathrm{A}(\mathrm{Cl})$ systems, for which appreciable distortions from tetrahedral symmetry have been reported (Gruen and McBeth 1963), also lie in the same neighbourhood. Secondly, the Al-A(F) systems are seen to lie in a separate region of the map. With decreasing concentration of $\mathrm{AlF}_{3}$ below $\mathrm{c}=1 / 2$, the $\left(\mathrm{AlF}_{4}\right)^{-}$ tetrahedral complexes in these systems are gradually superceded by $\left(\mathrm{AlF}_{6}\right)^{3-}$ octahedral complexes, the two types of complexes being in coexistence in the range $1 / 4<c<1 / 2$ (Gilbert, Mamantov and Begun 1975). This behaviour is quite different from that shown by the $\mathrm{Y}-\mathrm{A}(\mathrm{Cl})$ systems, where $\left(\mathrm{YCl}_{6}\right)^{3-}$ octahedral complexes are dominant at $c=1 / 4$ and persist with gradual distortions associated with edge sharing as $c$ is increased up to $c=1$ (Papatheodorou 1977).

It is also of interest to notice the correlation between the order of the various systems along the main diagonal in the map in Figure 3, which classifies the complexing behaviour of mixtures at stoichiometric composition, and the known structural behaviours of pure polyvalent metal halide melts. Starting from the top right-hand end, we first meet $\mathrm{AlBr}_{3}$, which melts from a molecular solid of $\mathrm{Al}_{2} \mathrm{Br}_{6}$ units into a molecular liquid, and $\mathrm{AlCl}_{3}$, which melts from a mainly ionic lnyer 
structure into a molecular liquid of $\mathrm{Al}_{2} \mathrm{Cl}_{6}$ units (see for instance Ubbelohde 1978). The $\mathrm{ZnCl}_{2}$ melt, according to the neutron diffraction data of Biggin and Enderby (1981a), has instead a tetrahedrally coordinated network-like structure, accompanied by very high viscosity and very low ionic conductivity. Among the systems that are next met along this path in Figure 3, the liquid structure hai also been determined by neutron diffraction for $\mathrm{MgCl}_{2}$ (Biggin, Gay and Enderby 1984), $\mathrm{NiCl}_{2}$ (Newport, Howe and Wood 1985) and $\mathrm{NiBr}_{2}$ (Wood and Howe 1988). Essentially fourfold coordination and traces of intermediate-range order, as reflected in a prepeak in the $M$ - $M$ partial structure factor at wavenumber $k \approx 1 \AA^{-1}$, are present in these melts as in $\mathrm{ZnCl}_{2}$. However, various other observed structural features and, in the case of $\mathrm{MgCl}_{2}$, the measured values of transport coefficients, which are typical of non-associated molten salts, show that a fairly rigid ionic network is no longer present. Similar structural features are observed in molten $\mathrm{NiI}_{2}$, accompanied by significant penetration of $\mathrm{Ni}^{2}+$ ions into the first coordination shell of $\mathrm{Ni}^{2+}$ (Wood, Howe, Newport and Faber 1988). The liquid structure of $\mathrm{MnCl}_{2}$, though not fully known, closely resembles that of $\mathrm{MgCl}_{2}$ in those features that have been determined by neutron diffraction (Biggin et al 1984). Finally, the liquid structure of molten $\mathrm{CaCl}_{2}$ (Biggin and Enderby 1981b), with an average coordination number of 5.4 for the cation, appears to be of a transitional type towards the cation-dominated structures of the strongly ionic melts of $\mathrm{SrCl}_{2}$ (McGreevy and Mitchell 1982) and $\mathrm{BaCl}_{2}$ (Edwards, Howe and Enderby 1978). The results of neutron diffraction experiments on pure melts inside the pocket of stable octahedral coordination bracketed by $\mathrm{YCl}_{3}$ and $\mathrm{CrCl}_{3}$ in Figure 3, now being completed for lanthanide chlorides (Saboungi and Price 1988, private communication), will clearly be of great interest.

Let us now turn to the set of $\mathrm{M}-\mathrm{Li}(\mathrm{Cl})$ systems, included by us in the intermediate class, which are seen to cluster in the bottom right-hand corner in Figure 2 and to lie 
just above the upper edge of the main stability strip in Figure 3. The optical absorption experiments show stable fourfold coordination for divalent $\mathrm{Cu}, \mathrm{Ni}, \mathrm{Cu}, \mathrm{Fe}$ and $\mathrm{Mn}$ ions in a solvent which is a molten mixture of $\mathrm{LiCl}$ and $\mathrm{KCl}$ near eutectic composition (Gruen and McBeth 1963). Infrared absorption data in the case of $\mathrm{Cu}$ (Wilmhurst 1963) and thermodynamic data in the other cases (Papatheodorou and Kleppa 1970 and 1971a, Dutt and Østvold 1972, Østvold 1972b) confirm stability of complexes in the $\mathrm{KCl}$ solvent but are against it in the $\mathrm{LiCl}$ solvent. Optical absorption data on $\mathrm{Ni}-\mathrm{Li}(\mathrm{Cl})$ indicate marginal stability for $\left(\mathrm{NiCl}_{4}\right)^{2-}$ in this system (Smith and Boston 1965). We also note the apparent conflicts between enthalpy data (Kleppa and McCarty 1966) and Raman scattering data (Brooker and Huang 1980) for $\mathrm{Mg}-\mathrm{Li}(\mathrm{Cl})$, between enthalpy data (Papatheodorou and Kleppa 1971b) and Raman scattering data (Clarke et al 1972) for $\mathrm{Cd}-\mathrm{Li}(\mathrm{Cl})$, and between infrared absorption data (Wilmhurst 1963) and Raman scattering data (Ellis 1966) for $\mathrm{Zn}-\mathrm{Li}(\mathrm{Cl})$. The location of these three systems in Figure 3 might suggest fairly strong complex stability. In the case of $\mathrm{Zn}-\mathrm{K}(\mathrm{Cl})$ we have felt that the conflict between infrared absorption (Wilmhurst 1963) and Raman scattering (Bues 1955, Ellis 1966) ought to be resolved in favour of complex stability.

Finally, the $\mathrm{Cr}$ ion deserves special notice. As already pointed out, optical absorption spectra show that its coordination depends on its valence state, yielding stability for $\left(\mathrm{CrCl}_{4}\right)^{2-}$ complexes of distorted tetrahedral shape and instability for $\left(\mathrm{CrCl}_{4}\right)^{-}$- complexes. Our classifications make no provision for such dependence of complex stability on the number of valence electrons. The importance of this variable in structural stability problems has been stressed for solids by Villars (1983, 1984,1985 ) and is well known in relation to equilibrium molecular shapes (see for instance Andreoni et al 1985).

In summary, we believe that we have demonstrated the usefulness of the established methods of structure sorting in relation to a specific problem in liquid 
state structure, for which the ample experimental evidence permits meaningful statistics. The most useful structural map that we have been able to obtain is that shown in Figure 3, based on Pettifor's chemical scale approach. Of course, structural predictions are immediate for the systems not included in our maps, for which we have been unable to find relevant data.

Acknowledgments. This work was initiated during the 1988 Research Workshop in Condensed Matter, Atomic and Molecular Physics at the International Centre for Theoretical Physics in Trieste and completed during the stay of one of us (MPT) at the Argonne National Laboratory. The work at Argonne was supported by the U.S. Department of Energy, BES-Materials Sciences, under contract W-31-1.09-ENG-38. ZA wishes to thank Professor Abdus Salam, the International Atomic Energy Agency and UNESCO for hospitality in Trieste. MPT is grateful to Dr M. Blander for valuable suggestions and to Dro D. C. L. Price and M. L. J. Saboungi for useful discussions. He also acknowledges continued sponsorship by the Ministero dilla Pubblica Istruzione and the Consiglio Nazionale delie Ricerche of Italy. 


\section{References}

Akdeniz Z, Wang Li and Tosi M P 1988 Europhys. Lett. 5613

Andreoni W 1985 Hely. Phys. Acta 58226

Andreoni W, Baldereschi A, Bièmont E and Phillips J C 1979 Phys. Rev. B 2J 4814

Andreoni W and Galli G 1987 Phys. Rev. Lett. 582742

Andreoni W, Galli G and Tosi M P 1985 Phys. Rev. Lett. 551734

Begun G M, Boston C R, Torsi G and Mamantov G 1971 Inorg. Chem. 10886

Biggin S, Cummings S, Enderby J E and Blander M 1985 Proc. Molten Salts Symp. (Las

Vegas)

Biggin S and Enderby J E 1981a I. Phys. C 143129

Biggin S and Enderby J E 1981b I. Phys. C 143577

Biggin S, Gay M and Enderby j E 1984 I. Phys. 드 17977

Brooker M H 1975 I. Chem. Phys. 633054

Brooker M H and Huang C H 1980 Can. I. Chem. 58168

Bues W 1955 Z. anorg. allg. Chem. 279104

Bues W, Atapoor M and Popperl G $1983 \underline{163}^{\text {rd }}$ Meeting, The Electrochem. Soc. (San

Francisco)

Burdett J K, Price G D and Price S L 1981 Phys. Rev. B 242903

Car R and Parrinello M 1988 Phys. Rev. Lett. 60204

Chelikowsky J R and Phillips J C 1978 Phys. Rev. B 172453

Clarke J H R, Hartley P J and Kuroda Y 1972 I. Phys. Chem. 761831

Clarke J H R and Hester R E 1969 I. Chem. Phys. 503106

Dutt $Y$ and Østvold T 1972 Acta Chem. Scand. 262743

Edwards F G, Howe R A and Enderby J E 1978 I. Phys. C 111053

Ellis R B 1966 I. Electrochem. Soc. 113485

Emons H H, Horlbeck W and Kiessling D 1984 Z. anorg. allg. Chem. 510152

Gilbert B, Fung K W, Mamantov G and Begun G M 1975 I. Inorg. Nucl. Chem. 37921

Gilbert B, Mamantov G and Begun G M 1975 I. Chem. Phys. 62 9.11

Gruen D M 1964 in Fused Salts Ch. 5 (New York: McGraw-Hill) 
Gruen D M and McBeth R L 1963 Pure Appl. Chem. 623

Holm J L and Kleppa O J 1969 Inorg. Chem. 8207

Hong K C and Kleppa OJ 1978 I. Phys. Chem. 821596

Hvistendahl J, Klaeboe P, Rytter E and Øye H A 1984 Inorg. Chem. 23706

Ikeuchi H and Krohn C 1969 Acta Chem. Scand. 232230

Janz G J and James D W 1963 I. Chem. Phys. 38905

Kleppa O J and McCarty F G 1966 I. Phys. Chem. 701249

Maroni V A 1971 I. Chem. Phys. 554789

Maroni V A, Hathaway E J and C'airns E J 1971 I. Phys. Cnem. 75155

Maroni V A, Hathaway E I and Papatheodorou G N 1974 I. Phys. Chem. 781134

McCarty F G and Kleppa OJ 1964 I. Phys. Chem. 683846

McGreevy R L audd Mitchell E W J 1982 I. Phys. C 155537

Mooser E 1986 in Crystalline Semiconducting Materials and Devices p. 1 (New York:

Plenum)

Newport R J, Howe R A and Wood N D 1985 I. Phys. Cي 185249

Ostvold 'T 1972a I. Phys. Chem. 761616

Østvold T 1972b Acta Chem. Scand. 262788

Øye H A, Rytter E and Klaeboe P 1974 I. Inorg. Nucl. Chem. 361925

Øye H A, Rytter E, Klaeboe P and Cyvin S J 1971 Acta Chem. Scand. 25559

Papatheodorou G N 1975 Inorg. Nucl. Chem. Lett. 11483

Papatheodorou G N 1977 I. Chem. Phys. 662893

Papatheodorou G N and Kleppa O J 1970 I. Inorg. Nucl. Chem. 32889

Papatheodorou G N and Kleppa O J 1971a I. Inorg. Nucl. Chem. 331249

Papatheodorou G N and Kleppa O J 1971b Inorg. Chem. 10872

Papatheodorou G N and Kleppa O J 1974 I. Phys. Chem. 78178

Papatheodorou G N and Østvold T 1974 I. Phys. Chem. 78181

Papatheodorou G N and Smith G P 1973 I. Inorg. Nucl. Chem. 35799

Papatheodorou G N, Waernes O and Østvold T 1979 Acta Chem. Scand. A 33173

Pettifor D G 1984 Solid State Commun. 5131

Pettifor D G 1986 I. Phys. C 19285 


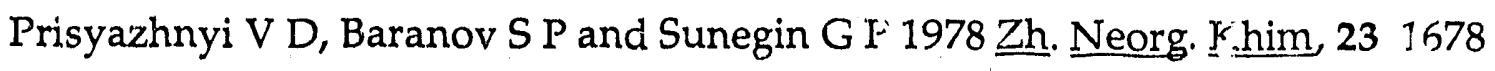

[English translation: Russian I. Inorg. Chem. 23 923]

Quist A S, Bates J B and Boyd G E 1972 I. Ph>rs. Chem. 7678

Rovere M and Tosi M P 1986 Rep. Progr. Phys. 491001

Sakai S, Nakamura T, Umesaki N and Iwamoto N 1984 Phys. Chem. Liquids 1467

Smith G P and Boston C R 1965 I. Chem. Phyc. 434051

St John J and Bloch A N 1974 Phys. Rev. Lett. 331095

Takahashi S, Maruoka K, Koura N and Ohno H 1986 I. Chem. Phys. 84408

Takahashi S, Muneta T, Koura N and Ohno H 1985 I. Chem. Soc. Faraday Trans. II 81. 319

Ubbelohde A R 1978 The Molten State of Matter (Chichester: Wiley)

Vaslow F and Narter. A H 1973 I. Chem. Phys. 594949

Villars P 1983 I. Less-Common Met. 92215

Villars P 1984 I. Less-Common Met. 9933 and 102199

Villars P 1985 I. Less-Common Met. 10993

Wilmhurst J K 1963 I. Chem. Phys. 391779

Wood N D and Howe R A 1988 I. Phys. 드 213177

Wood N D, Howe R A, Newport R J and Faber J Jr 1988 I. Phys. C 21669

Zunger A 1980 Phys. Rev. B 225839

Zunger A and CohenM L 1979 Phys. Rev. B 204082 


\section{Figure captions}

Figure 1. Stability map for fourfold cocrdination in molten $M-A(X)$ mixtures at "stoichiometric" composition ${ }_{r}$ according to the nodal radii scheme. The label $(\mathrm{Cl})$ has been omitted for the chlorides. Dots, circles and lozenges denote systems of strong stability, marginal or prsssible stability, and instability. The shaded line marks the approximate boundary of the region of instability, while the full lines approximately delimit the region of strong stability.

Figure 2. As in Figure 1, from the Zunger-Cohen pseudopotential radii. A special symbol has been used for the $\mathrm{Cr}$ ion, whose coordination depends on the valence state.

Figure 3. As in Figures 1 and 2, from Pettifor's chemical scale of the elements. The break in the vertical scales refers to the fluoride systems. The lozenges for the $\mathrm{La}-\mathrm{A}(\mathrm{Cl})$ systems give also the locations and the behaviour of the $\mathrm{Ce}-\mathrm{A}(\mathrm{Cl})$ systems. See the text for a detailed discussion of the various regions of the map. 


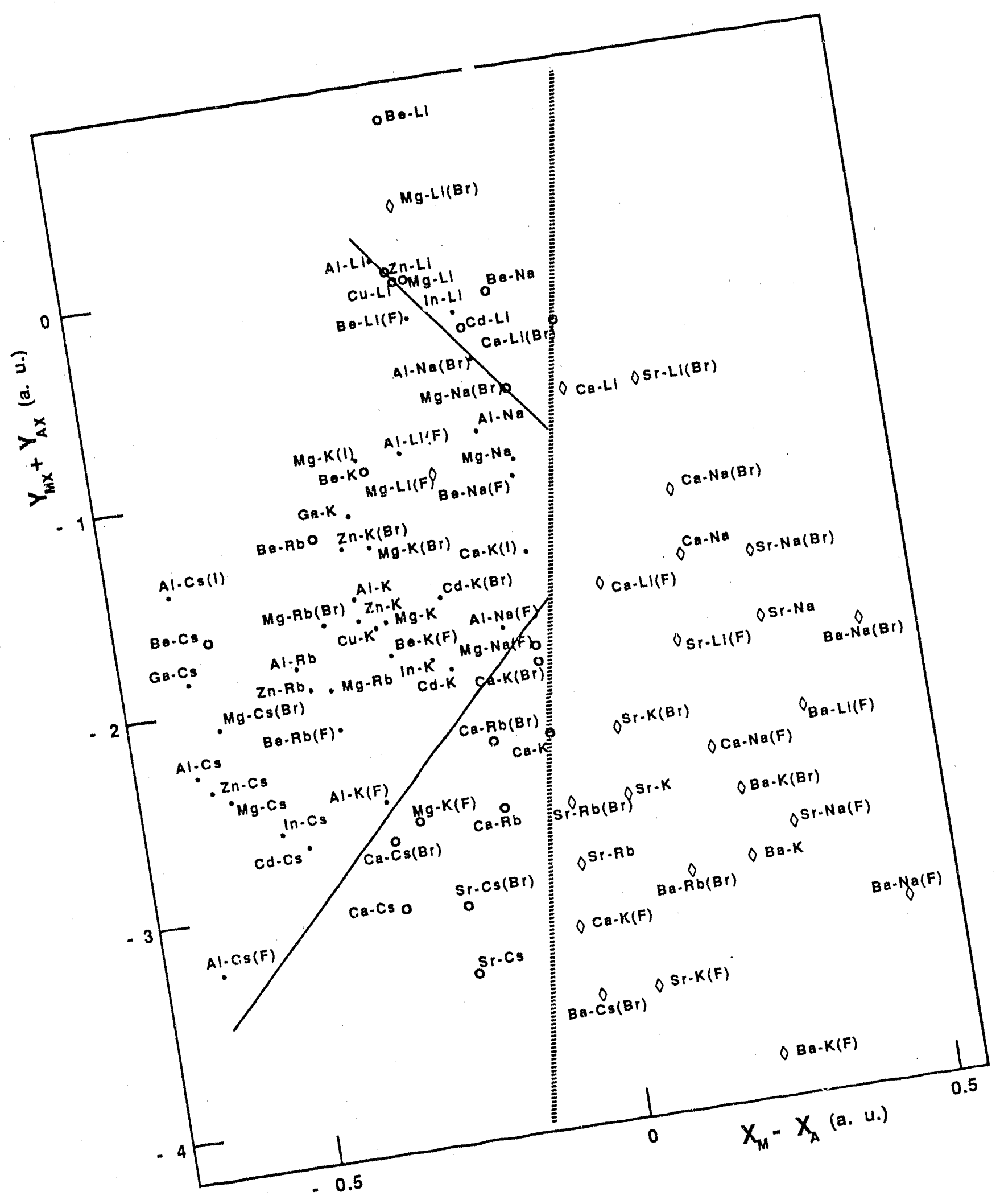




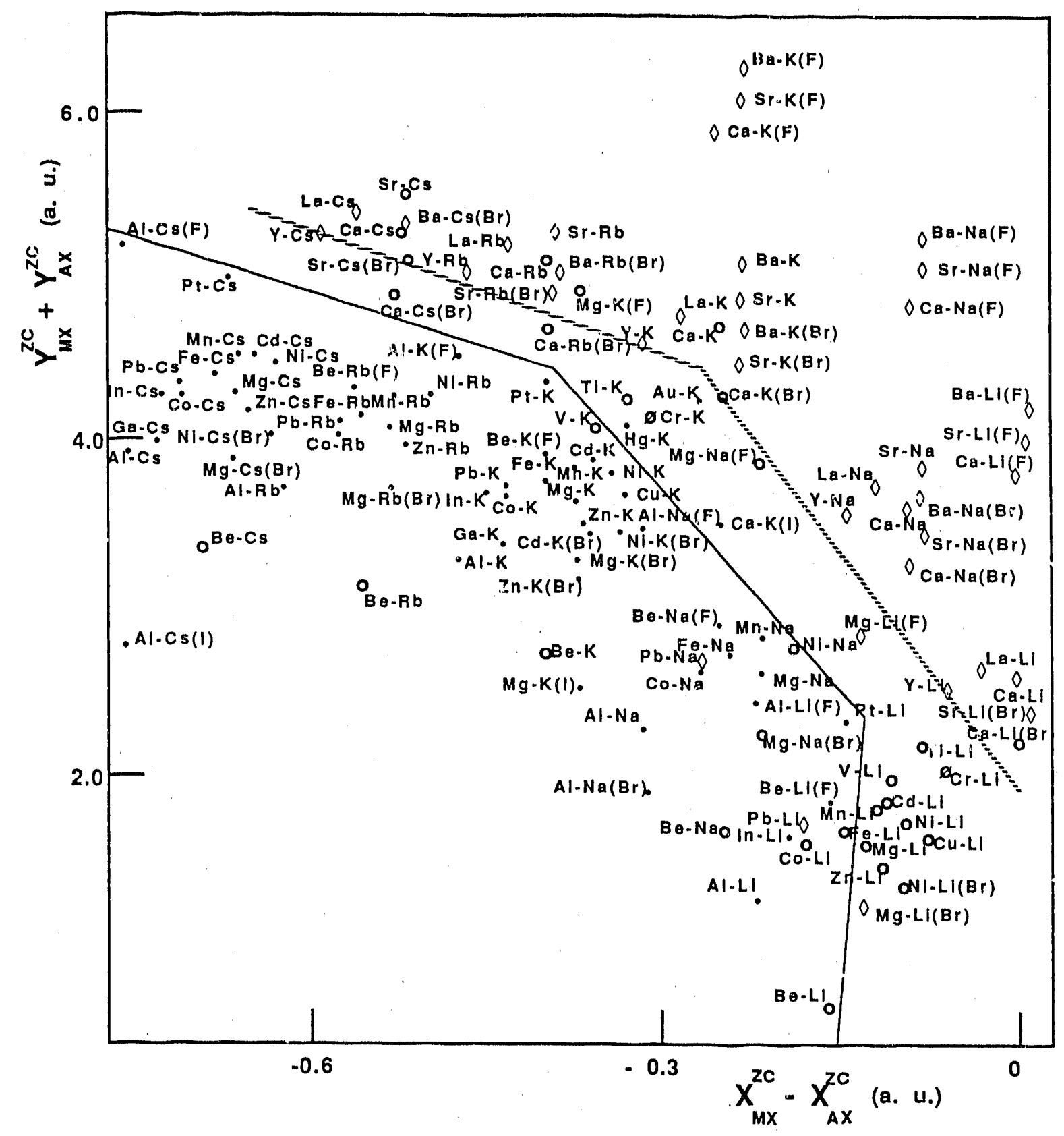




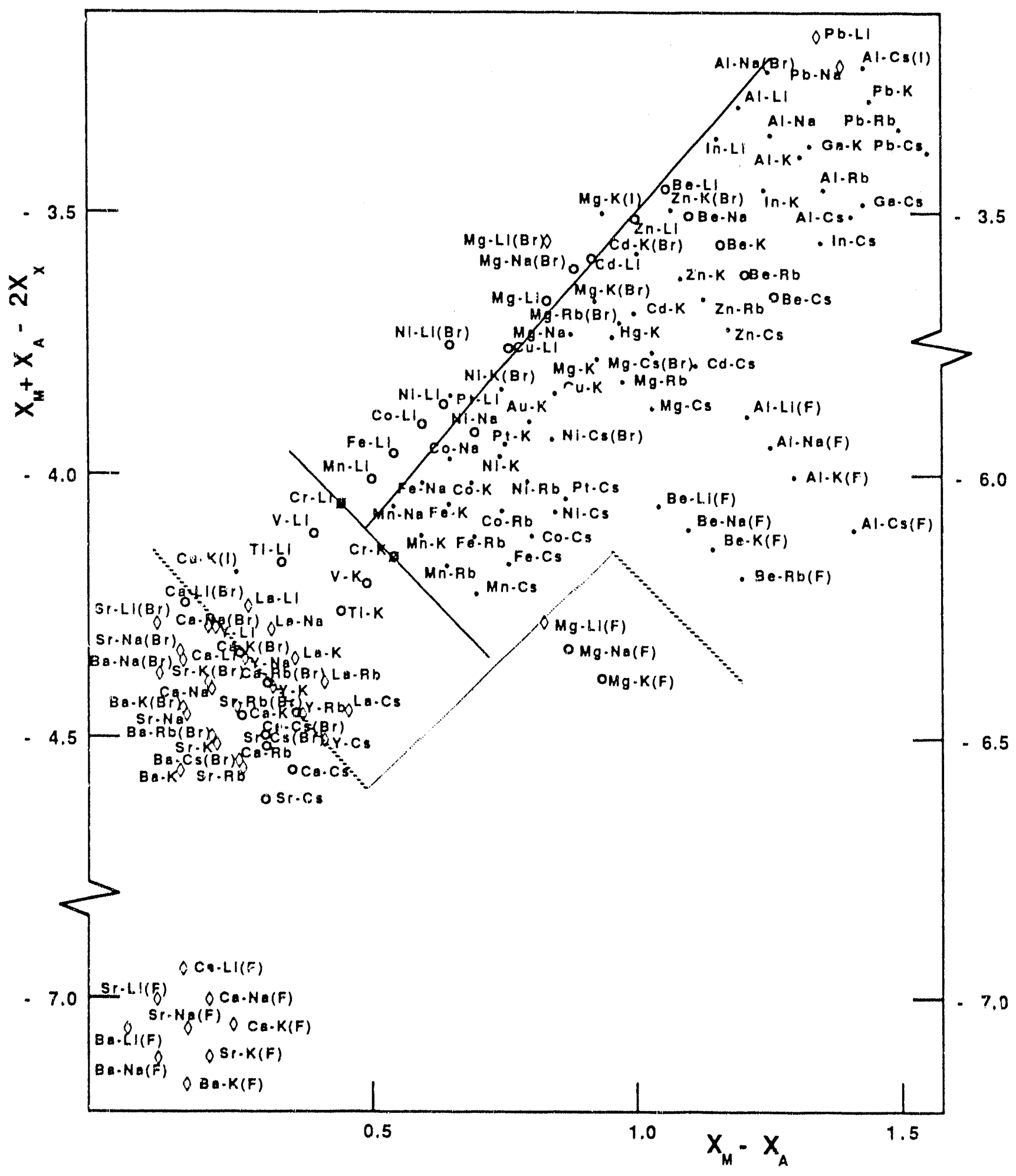



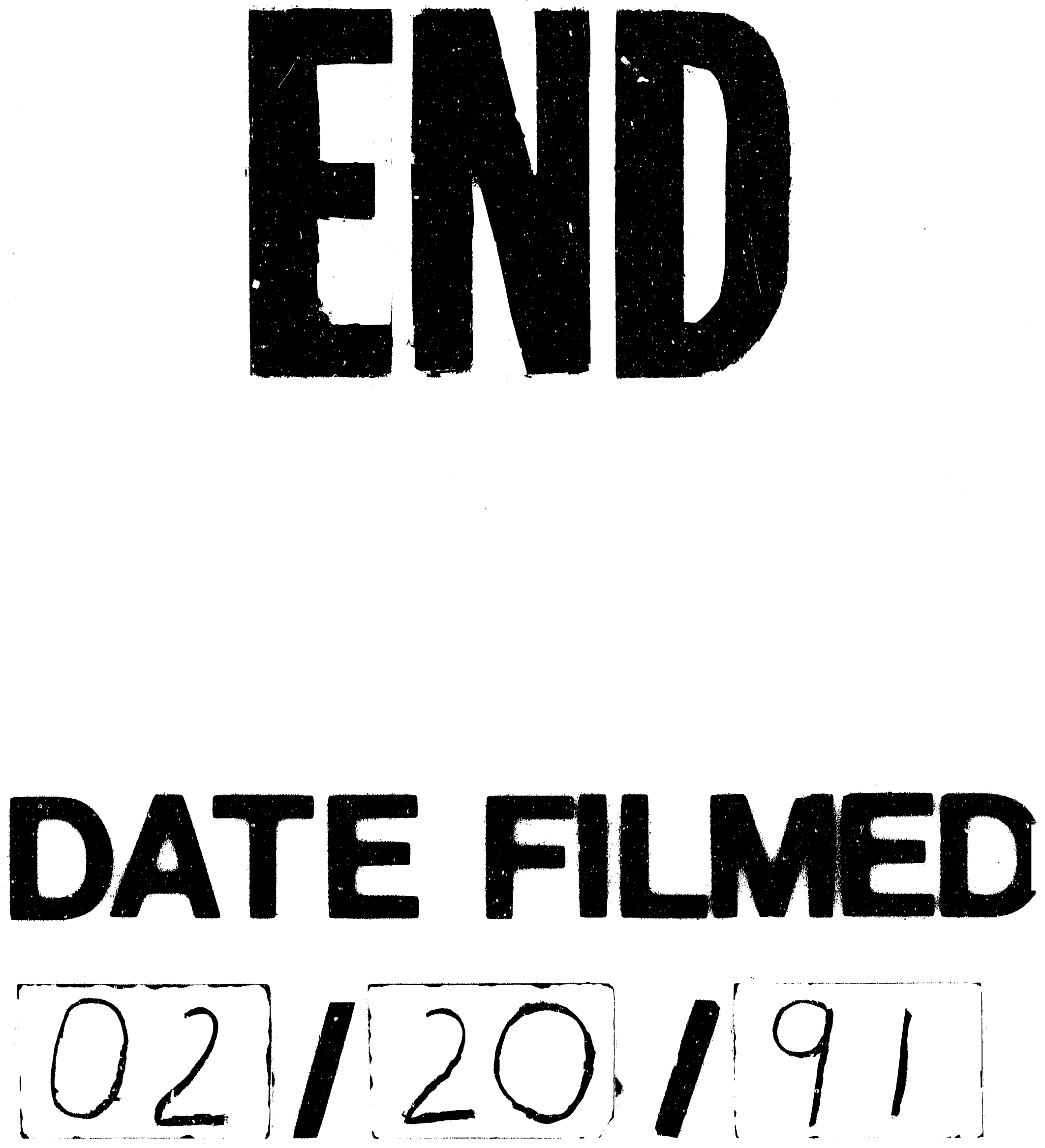
